\title{
Fas Mediated(CD95L) Periferal T-cell Apotosis Marker in Monitoring HIV-1 Disease Progression in Adults in Yaoundé, Cameroon
}

\author{
George Mondinde Ikomey ${ }^{1}$, Atashili Julius², Graeme Brendon Jacobs ${ }^{3}$, Martha Tongo Mesembe ${ }^{1}$, \\ Agnes Eyoh $^{1}$, Emilia Lyonga ${ }^{1}$, Okomo Assoumou Marie Claire ${ }^{1}$ \\ ${ }^{1}$ Departement of Microbiology/Immunology, Faculty of Medicine and Biomedical Sciences University of Yaounde, Yaounde, Cameroon \\ ${ }^{2}$ Department of Public Health, Faculty of Health Sciences, University of Buea, Buea, Cameroon \\ ${ }^{3}$ Faculty of Medicine and Health Sciences, Stellenbosch University, Tygerberg, South Africa
}

\section{Email address:}

Mondinde@yahoo.com (G. M. Ikomey), Atashili@yahoo.com (A. Julius), graeme@sun.ac.za (G. B. Jacobs), mtmesembe@yahoo.com (M. T. Mesembe), e_eyoh@yahoo.com(A. Eyoh), emilialyo@yahoo.co.uk (E. Lyonga), okomo2015@yahoo.fr (O. A. M. Claire)

\section{To cite this article:}

George Mondinde Ikomey, Atashili Julius, Graeme Brendon Jacobs, Martha Tongo Mesembe, Agnes Eyoh, Emilia Lyonga, Okomo Assoumou Marie Claire. Fas Mediated(CD95L) Periferal T-cell Apotosis Marker in Monitoring HIV-1 Disease Progression in Adults in Yaoundé, Cameroon. International Journal of Immunology. Vol. 4, No. 1, 2016, pp. 1-5. doi: 10.11648/j.iji.20160401.11

Received: November 21, 2015; Accepted: November 29, 2015; Published: March 22, 2016

\begin{abstract}
Fas (CD95) / FasL are hallmarks of apoptosis involvement in pathogenesis of HIV. We assess changes in soluble Fas /FasL, CD4 \% and HIV-1 viral load in patients prior to the initiation of antiretroviral therapy (ART) and 6 months thereafter. A prospective longitudinal study on sixty consented HIV-1 positive adults. sFas and sFasL levels were measured by ELISA. CD4 cell counts and HIV-1 viralloads were measured using standard methods. Samples were analysed according to the manufacturers' guidelines. There was a significant positive correlation between HIV-1 viral load and FasL at six months (M6) on treatment $[r=+0.49,(0.03)]$. There were no correlation between sFas/FasL and CD4 cell counts $[r=-33(0.16),-31(0.17)-$ 23 (0.03) respectively]. The significant correlation between sFasL and HIV-1 viral load at six months of ART suggests that sFasL could be a signal biomarker for HIV-1 disease progression. We have shown in this study that high levels of sFasL depict high HIV-1 viral loads and advance state of the HIV disease. These biomarker should be investigated further in other settings.
\end{abstract}

Keywords: sFasligands (CD95), Apoptosis, HIV, AICD, ART

\section{Introduction}

Monitoring treatment success of patients on ART is solely dependent on HIV viral load assays [1]. The CD4 absolute cell count and CD4 cell \% are routinely used in Cameroon and many other Sub-Saharan African countries as a baseline prior to treatment. They are also used for monitoring treatment outcomes due to limited HIV viral load testing facilities available. Immunological and virological responses are required for better evaluation of patient success, especially after 6 months of ART initiation.

Fas-Ligand (FasL, CD95L) is a homotrimetric membranemolecule. It is a type II membrane protein belonging to the Tumour Necrosis Factor (TNF) and the Nerve Growth
Superfamilies, (NGS). Their C-terminal regions are outside the cell, with a three cystein-rich domain (CRD) [3-4]. FasL are expressed only while the T-lymphocytes are activated. The expression of FasL is induced in T-cells through activation via their T-cell receptor (Fas, Apo-1, CD95) (4-6). The extracellular region of Fas has significant homology to the corresponding region of other members of the TNF family. Each FasL trimer binds three Fas receptor molecules on the surface of the targeted cells [4-5]. The Fas receptor (target cell) is the antagonist of FasLigand (effector cells). When they are cross-linked during the immune activation of T-Cells, it leads to an up-regulation of apoptosis of CD4. The Activated Induced Cell Death (AICD) pathways of apoptosis is involved in this up-regulation, leading to an uncontrolled depletion of CD4 T-cells, as witnessed in immune depressed 
HIV patients [10-11].

Recent studies have highlighted the biological interaction of many viral and host factors, such as host genetics, immune response and their involvement in the pathogenesis of HIV disease. Members of the TNFR super family could mediate pleiotropic biological processes, such as cell proliferation, differentiation, apoptosis and cytokine production [4-9]. Several other studies had shown a significant increase of Fas receptors and ligand levels in plasma or serum of HIV-1 infected individuals, compared to their negative control subjects [10-17]. These studies also demonstrated the involvement of the Fas/FasL pathways in predicting HIV-1 disease progression. In our previous studies in resource limited settings in Cameroon we demonstrated that Fasligand (CD95L) were better alternatives, compared to the commonly used $\mathrm{CD} 4$ absolute or $\mathrm{CD} \%$ for baseline and in monitoring disease progression in infants and adults on ART (23).

HIV-1 viral load testing is the gold standard test recommended for monitoring patients' success with ART [1822]. However, their availability, due to high cost, as demonstrated in our previous study in Cameroon [24] requires the need to identify alternative approaches for monitoring ART in resource-limited settings. The study objective was to assess the changes in sFasL, CD4 cell counts, CD4 \% and HIV-1 viral load prior to and after the initiation of ART.

\section{Materials and Method}

\subsection{Study Design}

This was a prospective longitudinal study conducted between September 2012 and February 2013. Sixty HIV positive patients were recruited from the Center for the Study and control of Communicable Diseases (CSCCD), Faculty of Medicine and Biomedical Sciences, University of Yaoundé, Cameroon. Patients were screened for CD4 cell count and HIV viral load and were referred from different health units around the city of Yaoundé, Cameroon. All participants were those earmarked for ART with their baseline CD4 cell counts below 350 copies/ml. Initiation of ART was taken at time (M0) and all patients were followed-up after 6 months of treatment (M6). Demographic information was collected for each participant using a standard questionnaire and consent form. Ten milliliters of whole blood were collected under standard conditions in EDTA anticoagulant tubes and 50 $\mu 1$ was used for CD4 absolute cell count and percentages. Plasma was obtained after centrifugation of whole blood at $12000 \mathrm{rpm}$ for 5 minutes. The plasma was separated in less than four hours after blood collection in EDTA anticoagulant tubes.

\subsection{Ethical Considerations}

Ethical clearance was obtained from the Cameroon National Ethics Committee (Reg 049/CNE/SE/2012). Participation in this study was voluntary. A signed consent form was obtained from all participants. All procedures were standard and only involved minimal risk to the participants. Study results were returned to the patients and incorporated into their medical records. The results were readily available to their medical practitioners.

\subsection{Measurement of sFas Levels}

Soluble Fas levels were assayed using a quantitative sandwich Enzyme-linked Immune-Sorbent Assay kit for both the receptors and the ligands (Quantikine ${ }^{\circledR}, R \& D$ Systems, UK), strictly using the manufacturer's instructions. The wavelength and optical density were measured at $450 \mathrm{~nm}$ using an ELISA reader (Sunrise Tecan Austria GMBH 5082 Microplate Reader) and all samples were assayed in duplicate. The concentration of sFas in plasma samples were determined extrapolating the results from a standard curve.

\subsection{HIV-1 Viral Load and CD4+Cell Counts}

We used the commercial kits manual (Amplicor 1.5, Roche diagnostics, Germany) an RT-PCR assay. This was performed with a prepared Master Mix containing oligonucleotide primers Specific to regions of the HIV-1 gag genes with upstream sense primers of (sk145) 5'(AGTGGGGGGACATCAAGCAGCCATGCAAAT3') and the downer stream antisense, (skcc1B) SKCC1B (5'TACTAGTAGTTCCTGCTATGTCACTTCC-3'). The detection and quantification was done using coated hybridization probes. The optical density and wave lengths were measured and extrapolated curves generated to calculate results. The minimum detection limit of the kits was $2.3 \log 10$. CD4+ counts were done using the Automated FAScount machine from Becton Dickinson (Abbott France) both the CD4 and Viral loads were done simultaneously to generate both baseline values. Samples were analysed based on the manufacturers' guidelines.

\subsection{Statistical Analysis}

Data were analysed using STATA version 11 (STATA, Corps Texas, USA). Six month changes in Fas ligand levels were compared to six month HIV viral load changes using the Pearson correlation coefficient. Changes of HIV viral load were considered significant with a $\log$ difference of 0.5 between two viral load scores. The Mann Whitney test was used to compare association.

\section{Results}

\subsection{Patient Demographics}

Of the sixty participants enrolled in the study, 38 (63.3\%; $\mathrm{n}=60)$ were female and $22(36.6 \% ; \mathrm{n}=60)$ male. Their ages range from 20 to 61 , with a mean of $34.3(\mathrm{SD}=7.8)$. The information is summarized in Table 1. All participants receive first line ART according to the WHO and Cameroon national guidelines.

\subsection{Baseline Data (Mo)}

\subsubsection{HIV Viral Load and SFasLigands Levels}

The HIV viral load levels ranged from 3.7 to $5.4 \log 10$ 
with a mean value of 4.8 , while the Fasligand concentration ranged from 51 to $321 \mathrm{pg} / \mathrm{ml}$ with a mean value of 153.7 (Table 2).

Table 1. Demographic data of study Population.

\begin{tabular}{lll}
\hline Gender & $\mathbf{N}=\mathbf{( 6 0 )}$ & $\mathbf{\%}$ \\
\hline Male & $38 / 60$ & 63.3 \\
Female & $22 / 60$ & 36.6 \\
Age Group(Years) & & \\
$20-25$ & $2 / 60$ & 3.3 \\
$26-31$ & $6 / 60$ & 10 \\
$32-37$ & $33 / 60$ & 55 \\
$<38$ & $19 / 60$ & 31 \\
Marital Statue & & \\
Married & $23 / 60$ & 38 \\
Single & $37 / 60$ & 61 \\
\hline
\end{tabular}

Table 2. Baseline and Six months Data.

\begin{tabular}{lll}
\hline Base line values & Log10/copies/ml/pg/ml & Means \\
\hline $\begin{array}{l}\text { HIV-1 viral load } \\
\text { FasLigand (CD95L/127) } \\
\begin{array}{l}\text { concentrations } \\
\text { Six months on ART }\end{array}\end{array}$ & $51-5.4$ & 4.8 \\
$\begin{array}{l}\text { HIV viral loads } \\
\begin{array}{l}\text { FasLigand (CD95L/127) } \\
\text { concentrations }\end{array}\end{array}$ & $1.3-3.4$. & 153.7 \\
\hline
\end{tabular}

\subsection{2. sFasR, CD4 Cell Counts}

sFas, CD4 levels ranged from 95 to $300 \mathrm{pg} / \mathrm{ml}, 200$ to $500 \mathrm{~mm} 3$ and $30-40 \%$, respectively. At six months HIV viral loads, sFas, sFasL and CD4 levels were 1.3 to 3.4 $\log 10,80$ to $290 \mathrm{pg} / \mathrm{ml}, 27$ to $231 \mathrm{pg} / \mathrm{ml}, 200$ to $650 \mathrm{~mm}$ and 30 to $45 \%$.

\subsection{Data at (M6)}

\subsubsection{HIV-Viral Load and FasL(M6)}

At six months on ART the HIV viral load and Fasligand levels showed a significant fall with their ranged of 1.3 to 3.4 $\log 10$ with a mean of 3.1 , while the Fasligand concentration ranged from 27 to $231 \mathrm{pg} / \mathrm{ml}$, with a mean of 88.1 (Table 2).

\subsection{2. sFasR, CD4 Absolute and CD4\% (M6)}

At six months sFas, CD4 levels ranged from 1.3 to 3.4 $\log 10,80$ to $290 \mathrm{pg} / \mathrm{ml}, 200$ to $650 \mathrm{~mm}^{3}$ and 30 to $45 \%$. These changes were not statistacally signiicant.

\subsection{Substantial Change After Six-Month in HIV Viral Load and Fasligands Levels}

The values show substantial change at after six-month with ranged from -3.5 to $+0.3 \log 10$ with a mean of -1.7 , while the FasL concentration ranged from -260 to $+81 \mathrm{pg} / \mathrm{ml}$. Twenty patients had $<1 \log$ change in HIV-1 viral load and a mean decrease of FasL levels of $-5.4 \mathrm{pg} / \mathrm{ml}$, while the forty patients had $>1 \log$ decrease in HIV-1 viral load and a mean decrease in Fas ligand concentration of $-87.2 \mathrm{pg} / \mathrm{ml}$ with a (p-value $=$ 0.06) (Table 2).

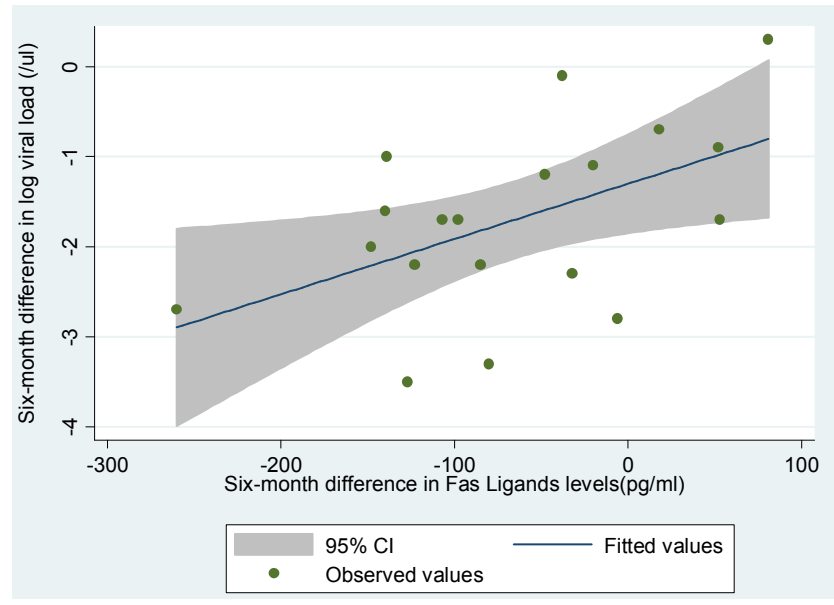

Figure 1. The scatterd plot illustrates the correlation between six-month changes in HIV-1 viral and SFasligand Levels. The X-axis shows the difference in HIV Viral load while the $Y$ - axis shows the sFasligand concentration. $(r=+0.49$, $p$-value $=0.03)$.

\subsection{Substantial Change After Six-Month in HIV Viral Load and sFasligands Levels}

The values show substantial change at after six-month with ranged from -3.5 to $+0.3 \log 10$ with a mean of -1.7 , while the FasL concentration ranged from -260 to $+81 \mathrm{pg} / \mathrm{ml}$. Twenty patients had $<1 \log$ change in HIV-1 viral load and a mean decrease of FasL levels of $-5.4 \mathrm{p} \mathrm{g} / \mathrm{ml}$, while the forty patients had $>1 \log$ decrease in HIV-1 viral load and a mean decrease in Fas ligand concentration of $-87.2 \mathrm{pg} / \mathrm{ml}$ with a $\mathrm{p}$-value $=0.06$.

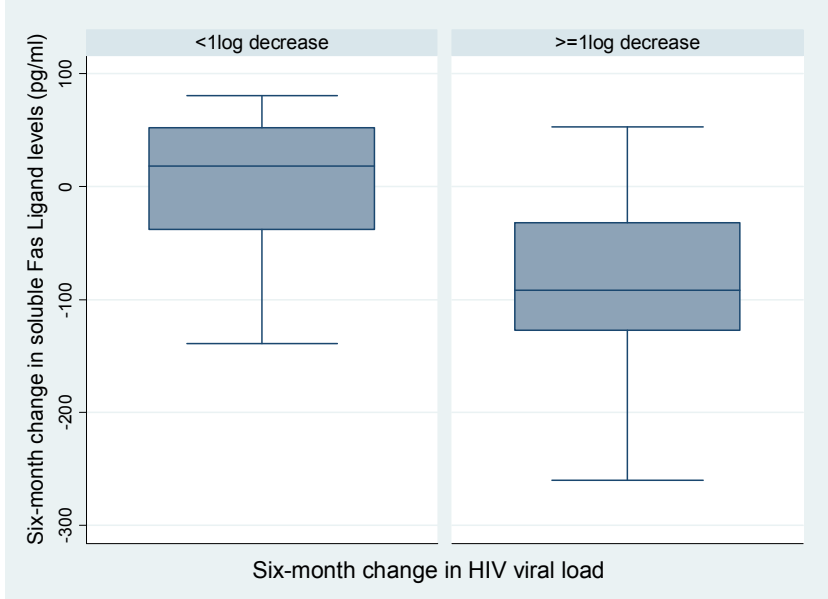

Figure 2. Box plot illustrates the substantial change in HIV-1 viral load and Fasigand using $a<$ and $>1$ Log. The middle horizontal lines represent the median concentrations of sFas ligands and HIV-1 viral loads $>1 \log$ and $<1 \log$.

\section{Discussion}

Fas and FasL play critical roles in the immune system, including the killing of pathogens in infected cells, causing death of absolute and potentially dangerous lymphocytes. They have also been shown to play critical roles in HIV-1 
pathogenesis [1-4]. This study aimed at assessing the sixmonth (M6) change in both FasL levels in comparison with HIV-1 viral load. Limited studies have been performed to evaluate the correlation between the apoptotic immunologic marker FasL (CD95L) and the gold standard virologic marker (HIV-1 viral load) used in monitoring patients on ART [5-9]. We have previously done a cost analysis to show the potential of using Fas and FasL as a cheaper alternative to evaluate ART outcomes (Ikomey et al., 2012; Ikomey et al., 2013).

The mean age of the study population was $34.4(\mathrm{SD} \pm 7.8)$, with $63.3 \%$ of patients being male and $36.6 \%$ female. Our results show that the majority of patients at baseline, before ART, had HIV-1 viral loads above $3.5 \log 10$ and FasL levels above $300 \mathrm{ng} / \mathrm{dl}$. Other studies have also shown high FasL levels of above $3 \log$ for treatment naïve patients [6]. The elevated levels of both biomarkers at baseline could be as a result of the high viral burden and immune activation of Tcells observed in naïve to early treated HIV-1 positive patients. These high levels of FasL could potentially indicate an increase in HIV-1 viral load and an advanced state of disease progression.

After six months on ART the HIV-1 viral load and FasL levels were significantly reduced, from 1.3 to $3.4 \log 10$ and 27 to $231 \mathrm{pg} / \mathrm{ml}$, respectively. The significant decrease in both the FasL and HIV-1 viral load levels could be interpreted as the result of the reduced viral burden due to ART. ART reduces the pressure of immune activation exerted on the cells, thereby reducing the apoptotic action of the Fas/FasL.

We have previously shown study results that demonstrated a positive correlation between HIV-1 viral loads and Fas ligand levels in HIV positive adults and children. This is the first longitudinal study we have done to evaluate FasL and HIV-1 viral loads over time [10-14]. We have shown the potential use of FasL in monitoring HIV disease progression in children, especially in resource limited settings.

We hypothesize that high levels of FasL in HIV-1 positive patients depict a high and clear signal of CD4 T-cell depletion. The results show that a high level of T-cell depletion could indicate a high HIV viral load and visa-versa.

The strength of this study is the fact that it was performed in Yaoundé, Cameroon, a resource limited setting in which alternative and cheaper methods are required to monitor HIV positive patients. The limitation of this study was the non inclusion of children and patients failing ART treatments. This will be done in a follow-up study.

\section{Conclusion}

The significant correlation between sFasL and HIV-1 viral load at six months of ART suggests that sFasL could be a better and more affordable alternative biomarker of HIV disease progression compared to $\mathrm{CD} 4$ absolute and $\mathrm{CD} \%$, currently being used in resource limited settings. We have shown in this study that high levels of sFasL depict high HIV-1 viral loads. And advance state of the disease. These biomarker should be investigated further in other settings.

\section{Authors' Contributions}

GMI conceived and designed the study, implemented sample collection and laboratory analysis, and wrote the first draft of the manuscript. MCOA, MJ contributed in the design and supervised laboratory analysis. JA participated in the design of the study, performed the statistical analysis and substantially revised the draft of the manuscript. MM, GJ contributed in the design, draft and wrote the manuscript. AE contributed in the design and participated in laboratory analysis. EL participated in laboratory analysis. BB participated in laboratory analysis. All authors read and approved the final manuscript.

\section{Acknowledgements}

The CSCCD laboratory, and the Chantal Biya reference hospital where this study and participants were recruited. The study was partially sponsored by a generous grant from the HIV Research Trust (United Kingdom) in 2015.

\section{References}

[1] Yu-Ting Lin Chia-Hung Yen Heng-Li Chen Yi-Je et al, The serologic decoy receptor 3 (DcR3) levels are associated with slower disease progression in HIV-1/AIDS patient. Journal of the formosom medical association 2015, 114, 498-505.

[2] UNAIDS. Report of global AIDS epidermic.2008, 2009.

[3] Fluur C, De Milito A, Fry TJ, Vivar N, Eidsmo L, Atlas A, Federici C, Matarrese P, Logozzi M, Rajnavölgyi E, Mackall CL, Fais S, Chiodi F, Rethi B. Potential role for IL-7 in Fasmediated $\mathrm{T}$ cell apoptosis during HIV infection. J Immunol. 2007 Apr 15; 178(8): 5340-50.

[4] Rethi B, Vivar N, Sammicheli S, Fluur C, Ruffin N, Atlas A, Rajnavolgyi E, Chiodi F. Priming of T cells to Fas-mediated proliferative signals by interleukin-7. Blood. 2008 Aug 15; 112(4): 1195-204. Epub 2008 Apr 25. First shared authorship.

[5] Vivar N, Thang PH, Atlas A, Chiodi F, Rethi B. Potential role of CD8+CD28- T lymphocytes in immune activation during HIV-1 infection. AIDS. 2008 May 31; 22(9): 1083-6.

[6] Gray L, Newell ML, Thorne C, Peckham C, Levy J; European Collaborative Study. Fluctuations in symptoms in human immunodeficiency virus-infected children: the first 10 years of life. Pediatrics. 2001; 108: 116-22.

[7] Dickover RE, Dillon M, Gillette SG, Deveikis A, Keller M, Plaeger-Marshall S, et al. Rapid increases in load of human immunodeficiency virus correlate with early disease progression and loss of CD4 cells in vertically infected infants. J Infect Dis. 1994; 170: 1279-84.

[8] Cohen JJ. Apoptosis: Physiologic cell death. J Lab Clin Med 1994; 124(6): 761-5.

[9] De Rossi A, Masiero S, Giaquinto C, Ruga E, Comar M, Giacca M, et al. Dynamics of viral replication in infants with vertically acquired human immunodeficiency virus type 1 infection. J Clin Invest. 1996; 97: 323-30. 
[10] Salvatori F, Masiero S, Giaquinto C, Wade CM, Brown AJ, Chieco-Bianchi L, et al. Evolution of human immunodeficiency virus type 1 in perinatally infected infants with rapid and slow progression to disease. J Virol. 1997; 71: 4694-706.

[11] Kalish LA, McIntosh K, Read JS, Diaz C, Landesman SH, Pitt $\mathrm{J}$, et al. Evaluation of human immunodeficiency virus (HIV) type 1 load, CD4 T cell level and clinical class as time-fixed and time-varying Markers of disease progression in HIV-1infected children. J Infect Dis. 1999; 180: 1514-20.

[12] Rich KC, Fowler MG, Mofenson LM, Abboud R, Pitt J, Diaz $\mathrm{C}$, et al. Maternal and infant factors predicting disease progression in human immunodeficiency virus type 1-infected infants. Women and Infants Transmission Study Group. Pediatrics. 2000; 105: e8.

[13] Goulder PJ, Jeena P, Tudor-Williams G, Burchett S. Pediatric HIV infection: correlates of protective immunity and global perspectives in prevention and management. Br Med Bull. 2001; 58: 89-108.

[14] Yu-Ting Lin Chia-Hung Yen Heng-Li Chen Yi-Je et al, The serologic decoy receptor 3 (DcR3) levels are associated with slower disease progression in HIV-1/AIDS patient. Journal of the formosom medical association 2015, 114, 498-505.

[15] Roederer M, Dubs JG, Anderson MT, RajuPA, Herzenberg LA, CD8 naive T cell counts decrease progressively in HIVinfected adults. $J$ Clin Invest. 1995; 95: 2061-6.

[16] Casella CR, Rapport EL, Finkel TH. Vpu increases susceptibility of human immunodeficiency virus type 1infected cells to fas killing. $J$ Virol. 1999; 73: 92-100.

[17] Samuelsson A, Broström C, van Dijk N, Sönnerborg A, Chiodi F. Apoptosis of $\mathrm{CD} 4+$ and $\mathrm{CD} 19+$ cells during human immunodeficiency virus type 1 infection - correlation with clinical progression, viral load, and loss of humoral immunity. Virology. 1997; 238: 180-8.

[18] Siegel RM, Chan FK, Chun HJ, Lenardo MJ. The multifaceted role of Fas signaling in immune cell homeostasis and autoimmunity. Nat Immunology. 2000; 1: 469-74.
[19] Koesters SA, Alimonti JB, Wachihi C, Matu L, Anzala O, Kimani J, et al. IL-7 Ralpha expression on CD4+ T lymphocytes decreases with HIV disease progression and inversely correlates with immune activation. Eur J Immunol. 2006; 36: 336-44.

[20] Yamana K, Bilim V, Hara N, Kasahara T, Itoi $T$, and Maruyama R, et al. Prognostic impact of FAS/CD95/APO-1 in urothelial cancers: decreased expression of Fas is associated with disease progression. Br J Cancer 2005; 93: 544e51.

[21] Rosenberg ES, Billingsley JM, Caliendo AM, Boswell SL, Sax PE, Kalams SA, et al. Vigorous HIV-1-specific CD4+ T cell responses associated with control of viremia. Science. 1997; 278: 1447-50.

[22] Finkel TH, Tudor-Williams G, Banda NK, Cotton MF Curiel $\mathrm{T}$, Monks C, et al. Apoptosis occurs predominantly in bystander cells and not in productively infected cells of HIVand SIV-infected lymph nodes. Nat Med1995; 1: 129-34.

[23] Alimonti JB, Ball TB, and Fowke KR. Mechanisms of CD4+T lymphocyte cell death in human immunodeficiency virus infection and AIDS. J Gen Virol 2003; 84: 1649-61.

[24] Holm GH, Gabuzda D. Distinct Mechanisms of CD4+ and CD8+ T-cell activation and bystander apoptosis induced by human immunodeficiency virus type 1 virions. $J$ Virol2005; 79: 6299-311.

[25] GM, Ikomey, MC, OkomoAssoumou, J,Atashili, M,Mesembe, et, al. Plasma Concentration of Soluble Fas receptors and ligands in relation to CD4+cell counts in HIV-1positive and negative patients in Yaounde Cameroon. BMC Res Notes. 2012; 5: 322.

[26] Gougeon ML, Montagnier L. Apoptosis in AIDS.Science. 1993; 260(5112): 1269-1270. doi: 10.1126/science. 8098552.

[27] Badri M, Wood R. Usefulness of total lymphocyte count in monitoring highly active antiretroviral therapy in resourcelimited settings. AIDS. 2003; 17(4): 541-545. doi: 10.1097/00002030-200303070-00009.

[28] Post FA, Wood R, Maartens G. CD4 and total lymphocyte counts as predictors of HIV disease progression. QJM. 1996; 89(7): 505-508. doi: 10.1093/qjmed/89.7.505. 